\title{
Documentário queer no Sul do Brasil: apontamentos gerais ${ }^{1}$
}

\section{Dieison Marconi e Cássio dos Santos Tomaim}

\section{Resumo}

Este artigo é fruto de dissertação desenvolvida no Curso de Mestrado do Programa de Pós-Graduação em Comunicação da Universidade Federal de Santa Maria (UFSM). Realizou-se um mapeamento de documentários com personagens lésbicas, gays, bissexuais, travestis e transexuais produzidos na região Sul do Brasil entre 2000 e 2014. A pesquisa objetivou analisar as representações LGBT, buscando compreender em que medida estes filmes partilham de narrativas/estéticas queer. Pôde-se observar que os 19 documentários analisados exploram as seguintes temáticas: memória/história, geração e envelhecimento, discriminações e resistências e, por fim, espaços de sociabilidades. Há um conjunto de documentários empenhados na incorporação política do outro-abjeto em uma cidadania generificada, sexuada e heteronormativa. De outro lado, existe um grupo de documentários experimentais (performáticos, poéticos e reflexivos) dispostos a quebrar com as inteligibilidades e normatividades culturais de sexo/gênero.

\section{Palavras-Chave}

Documentário queer. Estética. LGBT. Sexo/gênero.

Dieison Marconi I dieimarconni@gmail.com Doutorando no Programa de Pós-Graduação em Comunicação e Informação da Universidade Federal do Rio Grande do Sul, Brasil. Realizou Mestrado em Comunicação Midiática pelo Programa de Pós-Graduação em Comunicação da Universidade Federal de Santa Maria, Brasil.

\section{Cássio dos Santos Tomaim ।}

cassiotomaim@gmail.com

Doutor em História pela Universidade Estadual Paulista - Franca, Brasil. É professor pesquisador nos Programas de Pós-Graduação em Comunicação e em História, ambos da Universidade Federal de Santa Maria, Brasil. Também atua como professor no Departamento de Ciências da Comunicação da Universidade Federal de Santa Maria.

\section{Introdução}

No cinema e na fotografia, close é um plano fechado, íntimo, próximo e detalhado da personagem, de modo que ela ocupe expressivamente todo o cenário. No pajubá das travestis ou nas modernas gírias gays, close é dar pinta, chamar a atenção, é mostrarse, é exibir-se, é o bate-bate, é o dar close de travesti. É dentro destas duas linguagens que este termo traduziu o objetivo principal desta investigação: analisar de forma íntima e detalhada as representações das personagens LGBT nos documentários da região Sul do Brasil produzidos entre 2000 e 2014, tangenciando em que medida estes documentários partilham de uma estética queer. Tendo em vista que 0 filme documentário é historicamente renegado pela historiografia clássica do cinema brasileiro e pelos poucos estudos em cinema queer realizados no Brasil, este trabalho visa mostrar, problematizar e chamar a atenção para possíveis experiências de um documentário queer no país, um documentário que pode contribuir com retratos fílmicos para contrassexualizar 
as imagens das sexualidades, do gênero, da corporalidade, do desejo, do afeto, do erotismo e da pornografia. Postulado este horizonte, interessou a este estudo questionar: se há ou não uma correção dos estereótipos, estes documentários do Sul também dão visibilidade e legitimidade a identificações queer? Como se dá 0 jogo das identidades e diferenças nestas obras? Como são representadas essas vidas abjetas (BUTLER, 2011)? Estes filmes estão mais dispostos a representar suas personagens de maneira palatável e assimilacionista ou desejam incomodar as inteligibilidades de sexo/gênero? 0 que seria, afinal, um documentário queer?

Partimos do pressuposto de que é preciso olhar para o documentário como um produto cultural midiático, já que não basta afirmar que o cinema implica em uma construção. É preciso perguntar: construção para quem? E em conjunção com quais ideologias e discursos? É pelo fato do cinema ser "uma instituição, no sentido jurídico e ideológico, a uma indústria, uma produção significante e estética, a um conjunto de práticas de consumo" (JULIER; MARIE, 1995, p.17), que as representações de travestis, intersexuais, transexuais, bissexuais, lésbicas e gays figuradas na tela do cinema terão, sim, efeitos reais sobre a vida destes sujeitos.
Para Nichols, as representações dos sujeitos filmados nos levam a formular a seguinte pergunta: "Por que as questões éticas são fundamentais para o cinema documentário?". Formulada de outra maneira, a pergunta seria: "Que responsabilidade têm os cineastas pelos efeitos de seus atos na vida daqueles que são filmados?"(NICHOLS, 2012, p.32). Desse modo, ao olhar para 0 documentário através de uma perspectiva queer, essas perguntas ganham um adendo: 0 que um documentarista faz com as sexualidades, 0 gênero, 0 corpo e os afetos daqueles que (historicamente estigmatizados) estão agora sendo filmados? Por isso, a motivação desta pesquisa justificou-se, justamente, pela ausência desses olhares sobre os encontros (ou desencontros) do cinema documentário com uma estética queer. Tendo em vista que se deu e ainda se dá maior atenção às experiências queer e às representações LGBT no cinema ficcional, se esqueceu que 0 documentário também é uma "tecnologia do gênero" (LAURETIS, 1994).

Na construção do estado da arte da pesquisa, encontramos alguns trabalhos que afirmam haver experiências de filmes brasileiros que podem compartilhar de estéticas queer, no entanto, estas pesquisas possuem o recorte do cinema de

Este artigo é fruto da pesquisa intitulada "Documentário queer no Sul do Brasil (2000-2014): narrativas contrassexuais e contradisciplinares nas representações das personagens LGBT", de autoria de Dieison Marconi. 0 trabalho foi premiado na categoria Melhor Dissertação de Mestrado do Prêmio Eduardo Peñuela de 2016, oferecido pela Associação Nacional dos Programas de Pós-Graduação em Comunicação (Compós). A pesquisa foi orientada pelo Professor Doutor Cássio dos Santos Tomaim no âmbito do Programa de Pós-Graduação em Comunicação da Universidade Federal de Santa Maria (POSCOM/ UFSM), com bolsa de Demanda Social da Capes. 
ficção de longa-metragem² .0 que apresentamos aqui é, a partir do mapeamento da produção de documentários do Sul do Brasil produzidos com personagens LGBT entre 2000 e 2014, um estudo fílmico dessas representações LGBT e de suas experiências de estéticas queer. A escolha do espaço temporal (2000-2014) justifica-se, primeiramente, por fazer parte de um período pós-retomada do cinema brasileiro (NAGIB, 2002). Em segundo lugar, pelo despontar de um maior número de filmes nacionais comprometidos com representações mais diversas das pessoas LGBT (GARCIA, 2012). Em terceiro lugar, foi a partir de 2002 que houve um maior aquecimento da produção de documentários nacionais (MARUNO, 2008). E, em quarto lugar, pela configuração dos movimentos das pessoas bissexuais, transexuais, travestis, lésbicas e gays desta última década, as quais lutam por espaços midiáticos - entre eles, o cinema - para dar existência social aos seus próprios discursos (SIMÕES; FACHINI, 2009).

Dentro desse espaço temporal, foram encontrados 19 documentários (longa, média e curtametragem) com personagens LGBT realizados por produtoras, ONGs e coletivos ativistas do Sul do país. De modo geral, esses filmes constroem suas representações dentro dos seguintes eixos temáticos: 1) memória/história; 2) sexualidades, geração e envelhecimento; 3) subversões e resistência; e 4) territórios de sociabilidades. Contudo, também foi possível agrupar todos esses documentários em duas filiações estéticopolíticas. Há um conjunto de filmes que estão politicamente dispostos a perturbar e quebrar com os ordenamentos generificados e sexuados. São documentários dissidentes que explicitam um desejo maior de incomodar do que acomodar suas personagens aos níveis de inteligibilidade de sexo/ gênero e que, desse modo, podem ser identificados como documentários queer. Sua discursividade, forma e conteúdo também perpassam pelos documentários performáticos, poéticos e reflexivos (NICHOLS, 2008) e comprometemse com uma postura e de contratecnologia cinematográfica e de sexo/gênero. De outro lado, há um conjunto de filmes nos quais é possível perceber que suas representações estão marcadas por estratégias de reconhecimento através da assimilação e de uma estética palatável. São obras que se dispõem a apresentar uma denúncia e uma postura de resistência e de combate aos estereótipos e discriminações, aproximando-se da agenda política do ativismo LGBT brasileiro, o qual cobra reconhecimento através do aparelho do Estado. Então, também são filmes sobre sujeitos que exigem reconhecimento dentro de uma ordem reinante: uma cidadania sexuada, generificada e heteronormativa. 


\section{0 corpus da pesquisa}

Durante o processo de pesquisa documental em bancos de dados de cinematecas, dicionários, acervos, festivais, catálogos, Google e Youtube, buscou-se identificar se nos filmes mapeados havia personagens LGBT. Em seguida, tomamos como percurso metodológico 0 ato de conferir 0 ano de lançamento, a leitura dos títulos, a leitura das sinopses, a ficha técnica e também assistir aos trailers disponíveis. É importante ressaltar que, como todo trabalho de mapeamento é contínuo, e conforme novas fontes forem consultadas, reconhecemos que novos dados podem surgir. Além disso, como toda pesquisa tem suas limitações metodológicas, se fez necessário avançar para novas fases, logo, compreende-se que os filmes mapeados neste estudo constituem uma amostra confiável do cenário da produção de documentários com personagens LGBT da região Sul do país no período de 2000 a 2014. Para conhecimento prévio, também é preciso lembrar que os documentários produzidos em cursos universitários de Comunicação Social e Cinema e Audiovisual não foram considerados para esta pesquisa. Consideramos apenas aqueles filmes realizados por produtoras de cinema/audiovisual, grupos, ONGs ou coletivos de ativismo LGBT.

Após o mapeamento concluído, a procura por assistir aos filmes se deu em vários níveis: em um primeiro momento, buscou-se junto aos sites das produtoras, ONGs e coletivos que realizaram os filmes para saber se estes poderiam estar hospedados, assim como também consultou-se a disponibilidade dessas obras no youtube. Aqueles que não foram encontrados on-line foram solicitados junto aos realizadores que enviassem os filmes ou que indicassem outros canais em que estes pudessem ser assistidos. Por fim, no período 2000-2014, foram encontrados os seguintes documentários com personagens LGBT para fins de análise:

\section{Sobre sete ondas verdes espumantes}

(Bruno Polidoro e Cacá Nazário, 2013, RS)

\section{A dança da vida}

(Juan Zapata, 2008, RS)

\section{Castanha}

(Davi Pretto, 2014, RS)

4. Vida fora do armário

(Luciano Coelho, 2008, PR)

5. Gilda, o beijo na boca maldita

(Yanko Del Pino, 2008, PR)

\section{Família no papel}

(Fernanda Friedrich e Bruna Wagner, 2012, SC)

\section{Flores de 70}

(Fernando Cruxen, 2008, RS)

\section{Meu tempo não parou}

(Jair Giacomini e Sílvio Barbizan, 2008, RS)

\section{Um diálogo de Ballet}

(Filipe Matzembacher e Márcio Reolon, 2012, RS) 10. A turma

(Filipe Matzembacher e Márcio Reolon, 2011, RS) 11. A rua

(Filipe Matzembacher e Márcio Reolon, 2011, RS) 12. A rosa

(Filipe Matzembacher e Márcio Reolon, 2011, RS) 


\section{Preservativo}

(Filipe Matzembacher e Márcio Reolon, 2011, RS)

\section{Ivo e suas meninas}

(Beca Furtado, 2005, RS)

\section{A âncora}

(Filipe Matzembacher e Márcio Reolon, 2011, RS)

\section{Ser Mulher}

(Luciano Coelho, 2011, PR)

\section{A noite da cidade}

(Willy Shuman, 2010, PR) ${ }^{3}$

\section{Singularidades}

(Luciano Coelho, 2008, PR)

\section{Translucidx, 2013}

(Miro Spinelli, PR)

No período estudado, os estados do Paraná, de Santa Catarina e do Rio Grande do Sul produziram, juntos, 19 documentários com personagens LGBT. São treze filmes produzidos pelo Rio Grande do Sul, seis pelo Paraná e um filme por Santa Catarina. No Rio Grande do Sul, por exemplo, há um cenário interessante para estudar os treze filmes encontrados, pois a responsabilidade da produção da maioria das obras identificadas foi da Avante Filmes, produtora de cinema e vídeo composta por jovens graduados em cinema no Sul do país. Com endereço na capital gaúcha, a Avante
Filmes tem sua produção focada em temas como juventude, política, gênero, corpo e sexualidade. Além disso, estes jovens cineastas da Avante, como os diretores Filipe Matzembacher e Márcio Reolon, já trabalharam em coprodução com o grupo de ativismo LGBT Somos - Comunicação, saúde e sexualidade ${ }^{4}$ parceria que resultou em filmes como Preservativo (2011) e Um diálogo de Ballet (2011). A Avante também contribui para a construção do CLOSE - Festival Nacional de Cinema da Diversidade Sexual, organizado em Porto Alegre desde 2010. 0 evento entrou para a lista de festivais nacionais de cinema e arte LGBT, a exemplo do Mix Brasil, em São Paulo, o Rio Festival de Gênero e Sexualidade no Cinema, no Rio de Janeiro, o For Rainbow e o Curta o Gênero, de Fortaleza, e 0 Mostra Possiveis Sexualidades, de Salvador. Assim como no Rio Grande do Sul, a maioria dos filmes realizados pelo Paraná é do Projeto Olho Vivo, o qual produziu uma série de documentários com temáticas como preconceito racial, religião, arte popular e questões que dizem respeito às pessoas lésbicas, gays, bissexuais, travestis e transexuais.

Embora a produção desses filmes estenda-se ao longo de 14 anos, pode-se aferir que o pico de produção ocorreu nos anos de 2008 (seis filmes)

Após muitas tentativas sem sucesso de contato com o diretor e a produtora, A noite na cidade foi o único filme não encontrado. Desse modo, ficou inviável a sua análise no presente trabalho.

0 Somos - Comunicação, Saúde e Sexualidade é uma organização não governamental, fundada em 10 de dezembro de 2001, situada em Porto Alegre/RS/Brasil, criada a partir da reunião de um grupo de militantes advindos/as das áreas de Luta contra a Aids e do Movimento LGBT local, com a proposta de desenvolver ações sociais com abordagens direcionadas à Comunicação e Saúde. Atualmente, as ações da organização têm foco interdisciplinar atuando nas temáticas de Direitos Sexuais, Direitos Reprodutivos e Direitos Humanos a partir das áreas de Educação, Saúde, Justiça, Comunicação e Arte, tendo como missão trabalhar por uma cultura de respeito às sexualidades através da educação da sociedade e afirmação de direitos. Para mais informações: http://somos.org.br/ 
e 2011 (cinco filmes). Como o mapeamento elaborado para esta pesquisa demonstrou que 0 Rio Grande do Sul é o estado que mais produziu filmes com personagens LGBT entre 2000 e 2014, este número pode estar ligado ao que aponta um estudo mais geral, do qual esta pesquisa derivou: entre 1995 e 2010, constatouse que 0 estado gaúcho é o que mais produziu filmes de não ficção: foram 120 documentários, sendo 46 documentários de curta-metragem, 61 documentários de média-metragem e 13 documentários de longa-metragem. Paraná foi responsável pela produção de 96 documentários: 43 de curta-metragem, 44 de média-metragem e 9 de longa-metragem. Já Santa Catarina produziu 82 documentários: 23 de curta-metragem, 49 de média-metragem e 10 documentários de longametragem. Somando todos os filmes, entre 1995 e 2010, o estudo identificou que na região Sul do Brasil foram produzidos cerca de 300 filmes documentários e comprova que, ao contrário do que registra a historiografia clássica do cinema brasileiro, o cinema documentário produzido na região não foi e não é um conjunto de episódios isolados (TOMAIM, 2015, p. 25). Além disso, é possível apontar que o Rio Grande do Sul também figura como o terceiro estado que, desde a década de 1970, mais produz filmes (ficção e documentário) no Brasil, perdendo apenas para Rio de Janeiro e São Paulo. Até a década de 1970, o filme de não ficção de curta e média-metragem foi o carro-chefe da filmografia gaúcha, sendo, depois, superado pelo filme ficcional de curta e média-metragem (SILVA NETO, 2009; 2011).
Outras características gerais desse conjunto dos documentários mapeados para a presente pesquisa sobre a representação LGBT são: a maioria dessas obras foi beneficiada pelas legislações vigentes para 0 setor cinematográfico, seja federal, municipal ou estadual. No caso dos estados do Paraná e Rio Grande do Sul, são as capitais Curitiba e Porto Alegre que centralizam a produção da maioria dos filmes mapeados, e as estéticas tradicionais da cultura regionalista não são tão exploradas. No entanto, é interessante assinalar que, desde o final da década de 1990 até 0 final da primeira década do século XXI, as temáticas mais abordadas pelos documentários produzidos na região Sul do Brasil coincidem com os temas explorados pelos filmes mapeados para a presente pesquisa. Conforme o estudo apresentado anteriormente, em SC e PR o tema Memória/ História está na preferência dos realizadores, representando $20 \%$ e $25 \%$ das produções, respectivamente. Já no Rio Grande do Sul, os temas Comportamento (19\%) e Artes em geral (18\%) predominam, mas 14\% dos documentários gaúchos tratam de assuntos relacionados à Memória/História. Outros temas abordados por esta cinematografia regional são: Rio Grande do Sul - Questão Sociopolítica (12\%), Biografia (11\%); Paraná - Artes em geral (17\%), Biografia (16\%), Comportamento (16\%); Santa Catarina - Biografia (18\%), Comportamento (18\%), Artes em geral (17\%) e Natureza (10\%) (TOMAIM, 2015, p. 28).

Na medida em que assistíamos aos 19 filmes com personagens LGBT selecionados como corpus da 
pesquisa, suas características mais expressivas nos conduziram a pensar as personagens representadas dentro de determinados eixos temáticos, o que também viabilizou identificar diferentes caminhos e abordagens para pensarmos e problematizarmos a presença/experiência de narrativas e estéticas queer. 0 primeiro eixo temático (memória/história) contou com o estudo dos filmes que trazem no cerne das narrativas a construção de uma memória de personagens e sobre certos momentos históricos, como a cena LGBT na Porto Alegre dos anos 1970, 1980 e 1990 nos filmes Meu tempo não parou (2008) e Flores de 70 (2008); a história de vida da famosa Gilda, uma travesti das ruas de Curitiba retratada no filme Gilda, o beijo na boca maldita (2008); a literatura, a vida e a obra do escritor Caio Fernando Abreu no filme Sobre sete ondas verdes espumantes (2013); a imagem de Ivo, a primeira drag queen da cidade de Uruguaiana no filme Ivo e suas meninas (2005). 0 segundo eixo (envelhecimento LGBT) discutiu as explorações estéticas do curso da vida das pessoas LGBT e suas questões geracionais, como juventude e envelhecimento. Os filmes e personagens esmiuçados nesse eixo foram $A$ dança da vida (2008), Um diálogo de Ballet (2012), Singularidades (2008) e Castanha (2014). Já o terceiro eixo (discriminações e resistências) dedicou-se à análise das representações das personagens dos filmes inseridas em um contexto de reivindicações sociopolíticas mais demarcadas do que nos outros filmes, dando voz aos sujeitos que reivindicam a legitimidade de suas famílias homoafetivas, o reconhecimento de suas orientações sexuais, identidades e expressões de gênero. Vale destacar que nos filmes aqui analisados algumas tensões entre posturas queer e reivindicações de cunho militante identitário foram encontradas. 0s filmes que integram esse eixo temático são: Família no papel (2012), Vida fora do armário (2008), Ser Mulher (2007) e Translucidx (2013). 0 quarto e último eixo temático (sociabilidades LGBT) conta com a análise fílmica das personagens nos documentários que se dedicam a retratar as sociabilidades territorializadas de travestis, transexuais, bissexuais, lésbicas e gays, seja nas ruas de Porto Alegre, nos bares gays de Salvador ou em tradicionais casas de shows do Rio de Janeiro. Neste capítulo, foram analisados os documentários A turma (2011), A rosa (2011), A rua (2011), A âncora (2011) e Preservativo (2011).

\section{0 documentário queer em busca de um conceito}

0 cinema queer - na esteira da Teoria e dos ativismos queer - nasceu da contrariedade de muitos diretores, produtores e grupos de ativistas que, em resposta à discriminação latente chancelada pelo HIV/Aids da década de 1980, passaram a produzir um cinema ajustado e assimilacionista que figurava as pessoas LGBT de forma higienizada e normativa. Assim, grupos de cineastas dissidentes não apenas recusaram-se a sair de cena, como também conseguiram meios para produzir um cinema autodenominado queer. 
Em 1992, em um artigo na revista britânica Sight \& Sound, a crítica de cinema e feminista B. Ruby Rich utilizou o termo New Queer Cinema para conceituar a crescente produção cinematográfica com temáticas LGBT, difundida principalmente em cinemas independentes ou em festivais de cinema. A autora ousou mapear e descrever um cinema que quebrava com os estereótipos e as normatividades, com as convenções preconceituosas, igualitárias e, também, com as representações LGBT do cinema hollywoodiano. Eram filmes que ganhavam espaço em função do seu estranhamento:

Há traços em todos esses filmes de apropriação, pastiche e de ironia, assim como uma reelaboração da história que leva sempre em consideração um construtivismo social. Definitivamente rompendo com abordagens humanistas antigas e com os filmes e fitas que acompanhavam políticas da identidade, essas obras são irreverentes, enérgicas, alternadamente minimalistas e excessivas. Acima de tudo, elas são cheias de prazer. Elas estão aqui, elas são queer, acostume seus quadris a elas (RICH, 2015, p.20)

Karla Bessa (2014), inspirada por Rich, registra que alguns contextos e momentos históricos podem ajudar na compreensão do que seria um cinema queer no Brasil. Para além do HIV/Aids, a autora constata que uma das razões para 0 crescimento do cinema queer em vários países nos últimos anos foi 0 barateamento da produção fílmica com 0 uso de câmeras digitais e softwares de edição. A autora acredita que a ideia na cabeça e a câmera na mão continuam sendo um potencial transgressor que libera a criatividade para fora dos esquemas narrativos e cinemáticos dos filmes de alto custo. A maioria dos filmes mapeados por este trabalho, por exemplo, foi realizada em oficinas audiovisuais financiadas por leis de incentivo à cultura, por grupos de ativismo social e produtoras independentes, os quais se tornaram beneficiados pelas novas tecnologias digitais e pelo seu barateamento. Um terceiro motivo identificado por Bessa foi o fato de termos visto, nos últimos anos, o crescimento das representações midiáticas das personagens LGBT, como acontece com o beijo gay/lésbico da novela das oito. Segundo a autora, se, por um lado, isso ajuda na promoção da visibilidade dos que questionam a normatização das sexualidades, por outro, desencadeia reações violentas e acirram-se as lutas no campo das estéticas e das representações.

Apesar disso, Bessa não vê um consenso entre os diversos autores que se dispuseram a qualificar a estética ou a proposta política para um cinema queer e admite que definir exatamente o que é um cinema queer seria circunscrever um potencial que pode surpreender. Mas é por esse prisma da diferença cultural e sexual que sugerimos pensar na especificidade do documentário queer, enquanto uma produção que pode ser uma real subversão estética dos retratos fílmicos hegemônicos. Apoiada nas proposições do filósofo Paul Beatriz Preciado (2014), pensamos que um documentário queer, como ferramenta material e simbólica, deve assumir uma narrativa e uma estética contrassexual. Primeiramente - e de maneira negativa -, esses documentários se 
dedicam à desconstrução da naturalização das práticas sexuais das normatividades de sexo/ gênero. $\mathrm{E}$, em segundo lugar - e de maneira positiva -, esses documentários proclamam a equivalência (e não a igualdade) de todos os sujeitos (PRECIADO, 2014). Logo, o documentário queer não é um manifesto fílmico e contrassexual apenas por se posicionar de maneira antirrepressiva contra as operações do sistema sexo/gênero, mas por, principalmente, partilhar de uma narrativa contraprodutiva. Em outros termos, produz e representa experiências de vida alternativas à sexualidade normativa elaborada sob a visão das normatividades de sexo/gênero.

Teresa de Laurentis (1994) afirma que 0 sistema sexo-gênero ${ }^{5}$ é produzido por inúmeras tecnologias sociais, entre elas, o cinema. Neste caso, além de representar e reproduzir as normas de sexo-gênero cristalizadas nos espaços sociais e no imaginário coletivo, o cinema participa diretamente de sua produção e repetição. Logo, um documentário, para ser considerado queer, precisa ser uma contratecnologia deste sistema. $\mathrm{Ou}$, ainda, uma tecnologia de contraprodução de sexo/gênero e de oposição/resistência à práxis cinematográfica preconceituosa e à práxis assimilacionista (ou igualitária) que, muitas vezes, se misturam. Um documentário queer está, enfim, interessado na interrupção das produções e reproduções das normas generificadas e sexuadas através da incorporação política do outro-abjeto. Desse modo, ao se referir ao comportamento ético e estético nos documentários para imprimir uma estética queer, defendemos que é preciso problematizar as relações de poder que existem no seu processo de construção. Marcius Freire (2012), inspirado na filosofia do autor austríaco Martin Buber (2001), argumenta que se, para Buber, a vida atual é um encontro, "todo documentário, para tomar forma, tem que ser um produto de um encontro" (FREIRE, 2012, p.49). É nesse encontro entre o eu e o outro que o cinema documentário constrói seu argumento e demonstra as relações de poder entre 0 realizador, aquele que detém o domínio e os processos de produção/edição dos filmes, e as pessoas filmadas, que são submetidas a ele. Se a produção de um documentário é permeada por uma relação de poder, o próprio documentário é também uma situação estratégica de uma sociedade determinada (FOUCAULT, 1984) que dura o tempo de filmagem e coloca 0 outro diante de uma câmera para 0 "fazer falar" sobre seu sexo/gênero, aproximando-se das estratégias de confissão que Foucault cunhou de sientia sexualis. Isso faz do documentário um produto ocidental no qual o outro que fala, ou seja, se confessa, tem o dever de dizer tudo. Já aquele que tem o poder de fazer o outro falar e de submetêlo ao enquadramento fílmico será, então, o dono da "verdade sobre o sexo". Como um documentário queer contrassexualiza essas verdades? 


\section{Documentários queer no Sul do Brasil: desafios e desobediências às molduras da imagem}

A análise fílmica proposta para este trabalho priorizou exclusivamente 0 estudo das proposições/asserções sobre as imagens das personagens LGBT. Isso significa que se buscou compreender o ponto de vista destes documentários em relação àqueles personagens que eles (re)apresentam, descrevendo (desconstruindo) e interpretando (reconstruindo) as representações construídas para (e por) estes sujeitos filmados. Obviamente que, para entender os sentidos expressos pelas representações desses sujeitos, não pode haver uma desarticulação dos outros elementos fílmicos. Foi necessário considerar o contexto social e a posição do sujeito no enredo, os movimentos de câmera, 0 argumento fílmico, os planos e enquadramentos, os ângulos de filmagem, as trilhas sonoras, a utilização das cores, os ruídos e sons ambientes, iluminação, os diálogos e as metáforas sob as quais as personagens, elementos fílmicos principais da nossa análise, estão submetidas.

Os primeiros filmes a serem submetidos à análise foram os documentários que tratam das questões de memória/história ou, então, daqueles documentários que se apresentam como lugares de memória (NORA, 1993). Neste grupo, ficou evidente, por exemplo, como a maioria dos filmes [como Flores de 70 (2008), Meu tempo não parou (2008) e Gilda, o beijo na boca maldita (2008)] elabora uma valorização queer das personagens abordadas, constituindo-se, em maior ou menor grau, como um lugar de memória que evoca (atualiza) e reconhece 0 passado destes personagens. Gilda, enquanto vivia pelas ruas de Curitiba, foi um sujeito queer que não se conformou nem com as normas de inteligibilidade do sistema sexo/gênero e nem com o modelo identitário que hoje usamos para conceber o que é uma travesti, uma mulher transexual ou um homem gay. Ao resgatar a memória de Gilda, o documentário não força uma inteligibilidade cultural da personagem, de modo que ela permanece em seu não lugar. Já Meu tempo não parou e Flores de 70 assumem uma postura de abertura para a diferença e para 0 outro em sua totalidade e complexidade. Empreendem-se retratos fílmicos de personagens que resgatam, revisam, contestam e atualizam de maneira comprometida e orgânica os traços de uma memória viva. Mas os traços queer presentes nestas obras se devem muito mais pela postura de algumas personagens representadas do que pela construção/montagem fílmica. São documentários expositivos, com forte apoio em testemunhos e entrevistas alternadas, sem um uso mais criativo das imagens e sem nenhuma forma de experimentação audiovisual. É interessante destacar, também, que o tema Aids é revisitado na grande maioria dos filmes deste eixo temático. Esse dado revela que se 0 estigma da doença ainda acompanha a construção identitária das pessoas LGBT, esses filmes estão dedicados a combatê-lo através de um gesto de afirmação ressignificativo. 
Outra questão que volta e meia surgiu em boa parte das narrativas é a representação de como estes sujeitos viveram durante a ditadura civilmilitar no Brasil (1964-1985). A representação das violências que os mesmos sofreram por parte dos militares não se dá apenas em termos de perseguição política com base na desobediência às normas da política institucional vigente, mas também pelas desobediências às normas de sexo/ gênero praticadas nas boates, nos bares, nas ruas e em suas próprias casas. Há, sobretudo, uma vontade de memória de evitar que tais episódios caiam no esquecimento.

Já em Ivo e suas meninas (2008), embora 0 sujeito protagonista representado no filme tenha tido uma existência subversiva dentro de uma comunidade conservadora e dogmática na cidade de Uruguaiana (RS) nos anos 1940/1950, sua performatividade queer (BUTLER, 2003) é, no mínimo, sutilizada no documentário em função de assegurar o mito do homem gaúcho histórico. Isso demonstra que é preciso também ter em mente que, enquanto produto de uma sociedade que funciona a partir das normas de sexo/gênero, não é possível que estes filmes estejam completamente imunes aos discursos heterocentrados e generificados, principalmente aqueles que estão vinculados a um ponto de vista que já possui um projeto de memória a cumprir. ${ }^{6}$ Ivo foi uma drag queen (ou, talvez, uma travesti) que administrou uma casa de prostitutas em Uruguaiana. No entanto, em vez de explorar esta performatividade não normativa de sexo/gênero, o curta-metragem perde 0 seu tempo tentando provar a gauchidade da personagem. Permanece, então, essa tensão entre a performatividade não normativa (gay/ drag queen) e a performatividade normativa (0 gaúcho), sendo que esta é tão não original como qualquer outra performatividade de sexo/gênero.

Por fim, o documentário Sobre sete ondas verdes espumantes (2013) é o único filme deste eixo temático que não partilha do modus operandi tradicional de se fazer documentário. Ao contrário, além de considerá-lo um documentário que se ocupa de um lugar de memória afetiva para o escritor gaúcho Caio Fernando Abreu, 0 filme também é um documentário poético que movimenta vestígios históricos organizados através do itinerário das imagens, tal qual um filme de estrada, expondo também um diálogo entre cinema e literatura. 0 filme é composto pelos seguintes "capítulos": 1. a onda de solidão; 2. do espanto; 3. do amor; 4. da melancolia; 5. do transbordamento; 6. do ir-remediável e, por fim, 7. do Caio estrangeiro para além dos muros. Dentro destes capítulos, trechos de contos, cartas e bilhetes são lidos por amigas e amigos do escritor, sendo leituras e interpretações 
emocionalmente engajadas. Além disso, trechos dos textos de Caio Fernando Abreu surgem na tela, aliados às tomadas históricas, fotografias congeladas, materiais de arquivo e imagens colorizadas que passeiam pelas ruas e cidades e que valorizam o teor homoerótico presente na obra de Caio. Se Foucault (1988) e Butler (2003) reiteram que, ao longo da História, as instituições sociais trabalharam sistematicamente para adestrar os dóceis corpos da diferença, fazendo da sexualidade uma estratégia histórica de regulação e ordem social, o filme em questão contempla todo um corpo homoerótico e procura extrair do mesmo as diferentes experiências de erotização. Ainda que a obra explore um corpo designado de forma essencialista como masculino - e o reifica como masculino de modo erótico -, é através deste corpo que também podemos notar a descentralização das zonas erógenas, aquelas eleitas como únicas possíveis de prazer e gozo pelo sistema sexo/gênero (PRECIAD0, 2014). Os planos detalhes das diferentes partes dos corpos dedos, braços, quadris, coxas, pés, cintura, pernas e ombros - são representados na obra como zonas de desejo e prazer homoerótico masculino que desafiam, principalmente, as premissas da heteronormatividade?
Já no segundo eixo temático que tratou das questões geracionais das pessoas LGBT, como juventude de envelhecimento, analisaram-se os seguintes filmes: Um diálogo de Ballet (2012), Singularidades (2008), A dança da vida (2008) e Castanha (2014). Em Um diálogo de Ballet, constatou-se estarmos diante de um documentário reflexivo e poético que, ao colocar o jovem gay e 0 gay velho em um diálogo que é, ao mesmo tempo, um monólogo e um número de ballet diante de uma câmera estática, utiliza-se do próprio dualismo gay velho x gay jovem para criticá-lo. Mais do que nos outros filmes analisados, nota-se que $U m$ diálogo de Ballet questiona e desnaturaliza as ideias e os discursos sobre homossexualidades, geração e envelhecimento, interseccionando esses temas como ficções culturais que precisam ser ressignificadas. É neste sentido que este documentário pode ser considerado um filme queer: ao passo que preserva a categoria da identidade do homossexual velho, considerando-a significativa, dedica-se contra a reificação dos homossexuais velhos em direção às visões de homossexualidade e de envelhecimento como um terreno crítico da desconstrução do gênero/sexo.

No caso de Singularidades, o filme fixa-se em uma narrativa expositiva e marcada por

De acordo com Miskolci, a heteronormatividade é um conjunto de prescrições que fundamenta processos sociais de regulação e controle, até mesmo aqueles que não se relacionam com pessoas do sexo oposto. Assim, ela não se refere apenas aos sujeitos legítimos e normalizados, mas é uma denominação contemporânea para o dispositivo histórico da sexualidade que evidencia seu objetivo: formar todos para serem heterossexuais ou organizarem suas vidas a partir do modelo supostamente coerente, superior e "natural" da heterossexualidade. (MISKOLCI, 2009, p. 156) 0 conceito de heteronormatividade foi usado, pela primeira vez, por Michael Warner em 1991. Embora estejam inteiramente imbricados um ao outro, a heteronormatividade se difere do conceito de heterossexualidade compulsória elaborado por Adrienne Rich no ensaio "Heterossexualidade compulsória e existência Lésbica", lançado em 1980 (RICH, 2010). 
testemunhos intercalados. Nesse caso, é 0 comportamento não inteligível de Pedrinho que se alinha a uma postura queer ao desalinhar os polos opostos e estanques do masculino e do feminino. Borra estas fronteiras com seu equipamento de pedreiro durante o dia e com os vestidos e as camisolas que usa durante a noite. Já Rosangela, em sua maturidade de 43 anos, também constata visões mais diversas e não reificadas da lesbianidade. No entanto, 0 documentário lhe atribui a função de figurar 0 casamento monogâmico enquanto uma maneira ideal de se levar a vida, 0 afeto e a sexualidade desejo comum aos outros personagens do enredo fílmico, não sustentando a ideia de singularidades sugerida pelo título do filme. No caso de Georgete, ainda que submetida ao olhar exterior do cineasta, a personagem fala conscientemente em seu próprio nome e reivindica seu reconhecimento enquanto sujeito da diferença: uma travesti, negra e prostituta que está envelhecendo. Já em $A$ dança da vida, a aproximação com o queer fica a cargo de Nora, que se recusa a reificar seus desejos sexuais e afetivos como uma experiência particular alocada na dicotomia homossexualidade/ heterossexualidade. 0 mesmo serve para Castanha que, apesar de sua paródia demonstrar justamente o tom imitativo do gênero do qual fala Butler (2003), o filme elabora outros caminhos, como, por exemplo, o foco no enfrentamento com a morte através do ofício de ator do personagem.

No terceiro eixo temático, foram reunidos os filmes que tratam com maior ênfase das reivindicações de reconhecimento jurídico e social, fortalecendo o enquadramento fílmico das personagens sob o viés das minorias sociais. Ser Mulher (2011), por exemplo, subverte o discurso transfóbico e midiático de que mulheres transexuais não são mulheres. Contudo, reitera o modelo do que é ser mulher através de uma ideia unitária e homogênea da própria transexualidade e do gênero feminino. Já Translucidx é um documentário performático que também constrói sua estética narrativa em tom de reivindicação e resistência, mas, neste caso, a transexualidade é encarada como uma vivência performativa e prostética. Ao contrário dos outros documentários analisados (os quais são eminentemente expositivos), Translucidx também se mostra mais criativo e mais incômodo quanto à sua construção fílmica. Fruto de um edital do Ministério da Cultura para a produção de webdocumentário e com dez minutos de curta duração, o filme utiliza imagens caseiras/ autodocumentais produzidas por pessoas transexuais mescladas a cenas ficcionais e a uma narração intimista, subjetiva e poética. Não se pode ver o rosto das personagens nas cenas autodocumentadas, mas, sim, corpos "desajustados" na procura de "fazer" seu sexo/ gênero. Meninos transexuais vestem cuecas e exibem-se diante da câmera, fazem tentativas de usar pênis de silicone e tentam esconder os seios. As personagens experimentam, vestem, analisam, se movimentam diante da câmera como se estivessem, na verdade, diante de um espelho, demonstrando que o sexo/gênero não é tão somente um construto cultural performativo, 
como acredita Butler (2003), mas é também um construto prostético, pois se dá efetivamente na materialidade dos corpos (PRECIADO, 2014).

Já a maioria das cenas ficcionais contribui para a compreensão da engenharia cultural do sexo/gênero que fabrica corpos generificados, sexuados e heterossexuais, como se estes tivessem uma origem natural fundadora, como é o caso da cena dos manequins enfileirados. Logo, aqueles que nasceram com "erro de fábrica" - e sempre há falhas inconformadas no mecanismo de produção - produzirão inúmeros movimentos e "brincadeiras" ontológicas, "mutações" e subversões que desnaturalizam o sistema de produção desses sujeitos/corpos e transexualizam as operações que fixam as regras de reconhecimento e inteligibilidade, ainda que, como deve ser alertado, tudo ocorra dentro de um quadro rígido de transgressão e reiteração de certos discursos. Também é preciso dar atenção ao fato de que o diretor (que é transexual) compartilha de uma postura queer e também soube reconhecer/orientar seus atores e organizar as imagens autodocumentadas com um olhar queer. Segundo Nichols (2008), os documentários performáticos que exploram as temáticas de gênero e sexualidade se afastam de um programa político específico e de uma identidade específica. Transludicx se opõe aos filmes cuja estética narrativa está apoiada no "nós falamos sobre eles para nós". Em vez disso, ele proclama: "nós falamos sobre nós para vocês" ou "nós falamos sobre nós para nós". Por esse motivo, é interessante e frutífero destacar que é, em alguns casos, uma postura menos tradicional de construir um documentário, ou, então, um desejo performativo, poético ou reflexivo de se fazer documentário que pode garantir justamente uma estética/narrativa queer.

Já Família no papel (2012) busca desmistificar os conceitos de normalidade erroneamente aplicados para classificar famílias em todo o Brasil. Lançado o desafio, a obra mostra muitas famílias formadas por pessoas LGBT, principalmente gays e lésbicas, e expõe as batalhas e as dificuldades que ainda enfrentam para se tornarem no papel as famílias que já são no cotidiano de suas vidas compartilhadas. Então, como o próprio título sugere, 0 argumento fílmico está assertivamente alocado na defesa deste tema de interesse público e destes sujeitos que acionam dentro do documentário (e também fora dele) uma complexa rede de discursos localizados, principalmente em instituições jurídicas para serem reconhecidas como famílias "no papel". Sendo expositivo, o filme se abastece de uma estrutura retórica de testemunhos das personagens que narram experiências pessoais/subjetivas e, ao mesmo tempo, denunciam e cobram das instituições do Estado o direito ao casamento, à adoção e ao reconhecimento familiar.

As mesmas imagens e os argumentos repetemse em todos os testemunhos das personagens/ famílias entrevistadas: as famílias em suas casas, os casais vivendo um relacionamento 
monogâmico, educando os filhos com dedicação e carinho, alguns tirando crianças das filas de adoção, as crianças frequentam a escola, fazem festa de aniversário e compartilham o final de semana juntos. 0 que ocorre em termos fílmicos é a domesticação, a higienização e a homogenização de todos os arranjos familiares. Ao fazer isso, o filme negocia com uma moeda de duas faces. A obra não nega que o "casamento gay"/família homoafetiva altera e subverte 0 conceito de família como aquele constituído unicamente por pessoas heterossexuais cisgêneras. Mas, por outro lado, também é possível dizer que a representação fílmica do casamento/família homoafetiva é uma escolha que reitera a norma do casamento como modelo ideal de viver e compartilhar a vida, incluindo ideais como monogamia, fidelidade e criação de filhos. Inspirado em Miskolci (2007), é possível dizer que, quando Família no papel concentra-se na defesa de um tema de interesse público limitado pela concepção familiar (convencional e normativa) das relações amorosas e sexuais, a apropriação deste tema pelo filme também se revela com um objetivo político sem compromisso com a transformação da forma como a sociedade lida, de modo geral, com a variabilidade sexual e afetiva.

Já 0 último filme a ser analisado neste eixo foi Vida fora do armário (2008). 0 curta-metragem toca diretamente em um tema mais que recorrente no que diz respeito às histórias de vida das LGBT: o dilema do "armário". Trazendo cinco personagens LGBT (Kiko, Andressa, Kelly, Alcione

\section{e André Lucas), Vida fora do armário é um} conjunto de relatos sobre assumir/denunciar suas orientações sexuais e identidades de gênero. Sedgwick (2007) argumenta que o "armário" sustenta privilégios aos que não precisam esconder suas sexualidades/identidades de gênero e, ao mesmo tempo, é um dispositivo de regulação social que mantém em segredo as sexualidades e as subjetividades/identidades de gênero que "não são saudáveis". Desse modo, 0 armário do qual as personagens buscam sair é um paradoxo. Entendendo-se como sujeito desviante, permanecer no armário pode ser uma escolha para evitar maiores violências, constrangimentos e discriminações. Já sair do armário é um movimento de resistência porque, como argumenta Sedgwick, esses sujeitos assumidos, embora possam se deparar com manifestações de violência, ostentam de forma orgulhosa seus desejos frente ao outro que vê neste mesmo desejo um motivo para discriminá-lo, assim como possuem maior controle sobre o que virão a fazer ou dizer em relação a ele. Assim, o filme atesta uma comunhão de experiências das personagens em relação ao processo de discriminação e, acima disso, defende a felicidade de estar fora do armário.

Já o último eixo temático deste trabalho tratou das sociabilidades das pessoas LGBT, ancorandose na análise dos curtas-metragens expositivos/ observativos A rua (2011), A turma (2011) A âncora (2011) e A rosa (2011), todos dirigidos pelos já citados Filipe Matzembacher e Márcio 
Reolon (Avante Filmes, RS). Cada filme apresenta um espaço de sociabilidade LGBT em diferentes cidades do Brasil: Porto Alegre, Rio de Janeiro, Salvador e Maceió, e os quatro curtas compõem uma série de filmes intitulada Lugares. Além desses quatro curtas-metragens, outro filme que figura a mesma temática é Preservativo (também dirigido por Filipe Matzembacher e Márcio Reolon, 2011). Os quatro primeiros filmes tomam a rua, os bares, as boates e as casas de shows como territórios narrativos de vivências e vozes de sujeitos que estão em busca de um espaço no qual possam fazer seu gênero e viver suas afetividades/ sexualidades sem o temor de serem discriminados e violentados. Em resumo, são espaços representados como territórios de negociação, resistência e aceitação de um grupo sociocultural que inventa outras formas de coexistir e reexistir em cidades que os limitam às fronteiras circunscritas pelo preconceito/discriminação homo/transfóbica. Além disso, foi possível também identificar a maneira como esses documentários sublimam as conotações e vivências sexuais que esses lugares podem oferecer, em detrimento da valorização da representação das relações afetivas, artísticas, familiares e de amizade.

Já no curta-metragem Preservativo (2011), temos um garoto de programa, uma vendedora de sex-shop e um adolescente virgem que narram - enquanto assistimos à fabricação de um preservativo - suas visões, relações e experiências com 0 ato sexual. Em nenhum momento vemos os rostos das personagens, apenas ouvimos suas vozes em off enquanto a câmera acompanha a fabricação dos preservativos. Em suma, a narrativa estética deste curta-metragem está fundamentada na valorização da prática sexual por meio de três pontos de vista diferentes. A voz do garoto de programa que narra suas experiências sexuais com homens e mulheres em troca de dinheiro figura o valor financeiro. A representação da vendedora do sex shop, inicialmente, serve ao mesmo argumento: toma 0 ato sexual como um ritual ou prática que deve ser valorizado cotidianamente e, para isso, os objetos vendidos em sua loja podem significar algo mais para as relações sexuais. 0 terceiro personagem (o adolescente virgem) também reforça 0 argumento de valorizar 0 ato sexual através de uma visão romântica da relação sexual. Por fim, o questionamento aqui se dá pela ausência de uma imagem que se comunique, de fato, com os discursos das personagens. Não se trata de uma crítica ao uso da camisinha, seja no cotidiano dos sujeitos, seja na presente narrativa fílmica. Mas é latente a ausência de estéticas e estilísticas queer que foram deixadas de lado. Preservativo fica refém dos testemunhos, assim como aconteceu com boa parte de outros documentários aqui analisados.

\section{Considerações finais}

Refletir sobre como o documentário produzido na região Sul do Brasil tem representado as pessoas LGBT significa olhar para a tela tendo em mente que 0 olhar que esses realizadores lançam 
sobre esses sujeitos não é um olhar neutro, descompromissado e tão pouco sem efeitos reais sobre o mundo. Pelo contrário, produzir um filme, principalmente um documentário, implica em ação humana e social, em uma postura ética e política, desde o momento em que se escolhe 0 tema até os rituais de montagem e finalização. Além disso, o trabalho também nasceu de uma necessidade urgente de tentar responder o que se entende, afinal, por documentário queer e suas potencialidades estéticas e políticas.

Tendo em vista este horizonte, a análise fílmica aqui construída se deteve em olhar de modo crítico e queer para o lugar que todas as personagens LGBT ocuparam nas narrativas dos documentários mapeados. Em síntese, o lugar em cena concedido a essas personagens gira em torno de temas como memória, envelhecimento, sociabilidades e reivindicações sociais e políticas. Já as questões que emergem desses temas são de ordem comum, isto é, questões que sempre são colocadas em pautas quando se fala de pessoas LGBT. Essas questões são: saída do armário, identidade de gênero, relacionamentos sexuais, violência, discriminação, preconceito, direitos jurídicos e sociais, movimento social e Aids. Ao buscar constantemente se opor aos discursos de ordem preconceituosa, alguns desses filmes recaem na armadilha de ressignificar as representações desses sujeitos em termos hegemônicos, valorizando discursos e estéticas higienizadas e assépticas, em vez de reinventar e burlar o próprio regime discursivo que elege e define como as LGBT devem atuar ou se comportar para alcançarem um status de "vida viável" e serem, de fato, vistas como humanos. Desse modo, estes filmes representam suas personagens em torno de uma experiência unitária, essencializando suas identidades/diferenças e tomando-as como figuras minoritárias, postura que está em consonância com a atuação do movimento LGBT tradicional brasileiro e que tem seu horizonte de ideias de transformação social reduzido em termos de reconhecimento, principalmente exigindo distribuição de recursos sociais consolidados que revelam novas formas de regulação sexual (MISKOLCI, 2007). Foi possível notar que esta escolha estética vigora em filmes como Família no papel (2012) e Ser Mulher (2011), entre outros.

Há também aqueles filmes que não estão preocupados apenas em se opor aos retratos estereotipados, em elaborar uma representação positiva das LGBT ou reduzir sua criatividade a uma reificação identitária. Pelo contrário, estão interessados na interrupção das produções e reproduções das normas generificadas e sexuadas através da incorporação política do outro-abjeto. Ocupam-se de explorar a identidade, a diferença, o sexo, o gênero, o corpo e a sexualidade enquanto um terreno alternativo, contraprodutivo e contrassexual, como é o caso de Um diálogo de Ballet (2012), Translucidx (2013), Gilda, o beijo na boca maldita (2008) e Sobre sete ondas verdes espumantes (2013). É interessante notar também que, tanto em Um diálogo de Ballet quanto 
em Translucidx, a experimentação poética, reflexiva e performática de fazer documentário contribui para uma estética queer, não ficando reféns de posturas queer das personagens como aconteceu com Gilda, o beijo na boca maldita (2008), Flores de 70 e Meu tempo não parou (2008). Por fim e convencidos de que esta reflexão não se esgota aqui, 0 apelo feito neste trabalho foi, em resumo, o de sensibilizar nosso olhar para enfrentar todo este campo de batalha constituído de territórios fílmicos, os quais têm buscado, gradualmente, estender os domínios da representação das diferenças.

\section{Referências}

BUTLER, Judith. Problemas de gênero: feminismo e subversão da identidade. Rio de Janeiro, Civilizaçãa Brasileira, 2003.

Vida precária. Contemporânea,

São Paulo, n. 1 p. 13-33 Jan.-Jun. 2011

BESSA, Karla A teoria queer e os desafios às molduras do olhar. Cult, São Paulo, nº 193, p. 39-41, ago-2014.

BUBER, Martin. Eu e Tu. São Paulo: Centauro, 2001.

FOUCAULT, Michel. História da sexualidade I - A vontade de saber. Rio de Janeiro: Edições Graal, 1988. Microfísica do poder. Rio de

Janeiro: Edições Graal, 1984.

FREIRE, Marcius César Soares. Documentário: ética, estética e formas de representação. São Paulo: Annablume, 2012.

GARCIA, Wilton. Introdução ao cinema queer no Brasil. In: MACHAD0, Rubens. SOARES, Rosana de Lima. ARAÚJO, Lucia Corrêa. (Orgs). VII Estudos de cinema e audiovisual. São Paulo: SOCINE , 2012. p.457- 466.
JULIER, Laurent. MARIE, Michel: Lendo as imagens do cinema - São Paulo: Senac, 2009.

LAURETIS, Teresa de. A tecnologia do gênero. Tradução de Suzana Funck. In: HOLLANDA, Heloisa (Org.).

Tendências e impasses: o feminismo como crítica da cultura. Rio de Janeiro: Rocco, 1994. p. 206-242.

MISKOLCI, Richard. A Teoria Queer e a Sociologia: o desafio de uma analítica da normalização. In: Sociologias, Porto Alegre, ano 11, no 21, jan./jun. 2009, p. $150-182$

Pânicos morais e controle social: reflexões sobre o casamento gay. In: Cadernos Pagu no 28, p. 101-128, jan-jun de 2007.

MARUNO, G.R (2008) Cinema documentário brasileiro contemporâneo: análise do banco de Dados Nacional do Cinema (1994-2007). Dissertação de mestrado, Programa de PósGraduação em Multimeios. UNICAMP, Campinas, São Paulo, Brasil.

NAGIB, L. 0 cinema da retomada: depoimentos de 90 cineastas dos anos 90. São Paulo: Editora 34, 2002.

NICHOLS, Bill. Introdução ao documentário.

Campinas, SP: Papirus, 2012.

NORA, Pierre. Entre memória e história: a problemática dos lugares. Projeto História, São Paulo, PUC, n.10, p.7-28, dez. 1993.

PRECIAD0, Paul Beatriz. Manifesto contrassexual. São Paulo, N-1 edições, 2014

RICH, Adrienne. Heterossexualidade compulsória e existência lésbica. Bagoas, Natal. № 5, 2010, p.17-44.

RICH B. Ruby New Queer Cinema. In: New Queer Cinema - cinema, sexualidade e política. Murari, Lucas; Nagime, Mateus (orgs.) 1ª Edição Julho de 2015. SEDGWICK, Eve Kosofsky. Epistemologia do armário. Cadernos Pagu, Campinas, $n^{0} 28$, janeiro-junho de 2007, p.19-54. 
SIMÕES, Júlio Assis. FACHINI, Regina. Na trilha do Arco-Íris: do movimento homossexual ao LGBT. São Paulo: Fundação Perseu Abramo, 2009.

TOMAIM, C. S.. A retomada do documentário no Sul do Brasil: apontamentos sobre a produção de 1995 a 2010. Eptic (UFS), v. 17, p. 226-245, 2015.

\section{Bancos consultados durante o mapeamento dos filmes}

Acervo 0n-line da Cinemateca Brasileira

Acervo da Cinemateca de Santa Catarina

Acervo da Associação de Cinema e Vídeo do Paraná (Avec)

Acervo da Fundação de Cinema do Rio Grande Sul

(Fundacine)

Catálogos de filmes brasileiros da Agência Nacional de Cinema (Ancine)

Informes Anuais de lançamentos de filmes da Agência Nacional de Cinema (Ancine)

Dicionário de filmes brasileiros de curta e médiametragem (autoria Antônio Leão da Silva Neto)

Dicionário de filmes brasileiros de longa-metragem (autoria de Antônio Leão da Silva Neto)

Banco de títulos exibidos no Festival Mix Brasil

Banco de títulos do Festival É Tudo Verdade

Banco de títulos do Rio Festival Gay de Cinema

Banco de títulos exibidos no Festival

de Cinema Latino-Americano

Banco de títulos do Close - Festival Nacional

de Cinema da Diversidade Sexual

Banco de títulos do Florianópolis

Audiovisual do Mercosul

Banco de títulos exibidos do Festival

de Cinema de Gramado

Banco de títulos exibidos no Festival Internacional de curta-metragem da Associação Cultural Kinoforum.

\section{Filmografia e ficha técnica}

Sobre sete ondas verdes espumantes - Direção de Bruno Polidoro e Cacá Nazário. Porto Alegre/RS: Bezouro filmes, 2013. 1 DVD (74 min).

Direção: Bruno Polidoro e Cacá Nazario

Roteiro: Bruno Polidoro, Cacá Nazario, Tatiana Nequete

Produção: Jéssica Luz

Direção de Fotografia: Bruno Polidoro, Lívia Santos,

Luciana Baseggio, Roberta Sant'anna SD: Gabriela

Brevian, Lívia Santos e Luciana Baseggio

Montagem: Tatiana Nequete

Música: Haroldo Paraguassu, Jorginho do Trompete

Desenho e mixagem de som: Gabriela Brevian

Produtora/realização: Besouro Filmes

Meu tempo não parou - Direção de Jair Giacomoni e Sílvio Barbizan. Porto Alegre/RS: J.M Giacomini e Nuances, 2008, 1 DVD (65 min)

Direção: Jair Giacomini e Sílvio Barbizan

Roteiro: Jair Giacomini e Sílvio Barbizan

Produção: Vanessa Coimbra, Jair Giacomini, Sílvio

Barbizan e Célio Golin.

Direção de fotografia: Giovani Borba

Montagem: Giovani Borba, Jair Giacomini, Sílvio Barbizan

Música: Cristiano Hanssen

Desenho mixagem de som: Gabriela Bervian

Produtora/realização: J.M. Giacomoni e Nuances

Flores de 70 - Direção de Vinícius Cruxen. Porto Alegre/

RS: Somos, 2008. (25 min) Disponível em: https://www.

youtube.com/watch?v=ESwv-VL5 Ks. Acesso: maio. 2015.

Direção: Vinícius Cruxen

Roteiro: Vinícius Cruxen

Produção: Maitê Medeiros

Produção executiva: Ana Laura Albornoz

Direção de fotografia: Rafael Jaques

Direção de arte: Diego Steffani

Desenho e mixagem de som: Gabriela Bervian

Montagem: Fernando Nemoto

Música: Leonardo Vezon

Produtora/realização: ONG Somos 
Gilda, o beijo na boca maldita - Direção de Yanko Del Pino. Curitiba/PR: 2008 (15 min). Disponível em: https://www.youtube.com/watch?v=H9PwgxAtKLI. Acesso: abril. 2015.

Direção: Yanko Del Pino

Roteiro: Eduardo Prante

Pesquisa: Júlio Garrido

Produção: Geni Cruz

Fotografia e câmera: Yanko Del Pino

Montagem: Piu Gomes e Claudia Soares

Música: Celso Piratta

Ivo e suas meninas - Direção de Betânia Furtado. Porto Alegre/RS: RBS TV. 2005. (15 min) Acessado em: http://www.4shared.com/video/PzfawQPH/Historias_ Extraordinarias_-_RB.html. Acesso: maio. 2015.

Direção: Betânia Furtado

Roteiro: Betânia Furtado

Direção de Fotografia: Claudio Zigiotto

Música: Jean Presser

Desenho, mixagem de som, operação de aúdio: João Santos

Produção: Luana Fornaciari

Montagem e finalização: Claudia Azevedo, Márcio Riffel, Rafael Peçanha

Produtora/realização: RBS TV

Castanha - Direção de Davi Pretto. Porto Alegre/RS:

Tokio Filmes, 2014, (95 min).

Roteiro e Direção: Davi Pretto

Produção: Paola Wink

Direção de Fotografia: Glauco Firpo

Direção de Arte: Richard Tavares

Edição: Bruno Carboni

Desenho de Som: Tiago Bello

Som Direto: Marcos Lopes

Trilha Sonora Original: Diego Poloni e Tiago Abrahão

Um diálogo de Ballet - Direção de Filipe

Matzembacher e Márcio Reolon. Porto Alegre/RS:

Avante Filmes, 2012 (7min44)

Roteiro e Direção: Filipe Matzembacher e Márcio Reolon

Assistente de Direção: Amanda Moreno

Produção Executiva: Fernando Hart e Márcio Reolon
Direção de Produção: Fernando Hart

Assistente de Produção: Renata Schuh e Richard Tavares

Direção de Fotografia: João Gabriel de Queiroz

Assistente de Câmera: Filipe Rossato

Direção de Arte e Figurino: Manuela Falcão

Assistente de Arte: Ângelo Borsa

Preservativo - Direção de Filipe Matzembacher e

Márcio Reolon. Porto Alegre/RS: Avante Filmes, 2011,

(5 $\min 20)$

Argumento: Filipe Matzembacher

Roteiro, Direção, Montagem e Som: Márcio Reolon,

Filipe Matzembacher e Samuel Telles

Produção Executiva: Filipe Matzembacher e Márcio Reolon

Direção de Fotografia e Operação de Câmera: Samuel Telles

Singularidades - Direção de Luciano Coelho.

Curitiba/PR Projeto Olho Vivo, 2008, (35min47)

Diretor: Luciano Coelho

Produtor: Antonio Heraldo dos Santos, Ana Claudia

França, Camila Ghilardi Cardoso

Empresa produtora: Projeto Olho Vivo

Roteiro: Claudia Bordin Rodrigues, Mariza Tezelli,

Maristela Mitsuko Ono

Som: Ana Paula Cantelli, Ana Paula Lopes, Dante Luiz Roloff

Montagem: Francisco Carlos de Souza, Karin Patrícia

Soares, Luciana Patrícia de Morais

Fotografia: Marcio Luís Santos Turini, Rafael Leandro

de Oliveira

A dança da vida - Direção Juan Zapata. Porto Alegre/

RS: Zapata Filmes, 2007, (HD, 80min)

Direção, roteiro e produção: Juan Zapata

Duração: 80 min

Formato de captação: DV

Formato de exibição: HD, $35 \mathrm{~mm}$

Produção executiva: Rene Goya Filho e Juan Zapata

Montagem: Fabiano Cavalheiro

Direção de Fotografia: Juan Zapata

Trilha: Lucio Dorfman

Supervisão de som: Kiko Ferraz

Edição de Som: Chrístian Vaisz

Finalização de imagem: Marcelo Henriques 
Desenho gráfico: Guilhermo Dable

Produção: Estação Elétrica filme e vídeo

Coprodução: Zapata Filmes

Apoio: Armazém de Imagens e Kiko Ferraz Studios

Família no Papel - Direção de Fernanda Friedrich e

Bruna Wagner: Itajaí/SC: Tac Filmes, 2012, (52min09)

Direção e roteiro: Fernanda Friedrich e Bruna Wagner

Direção de Fotografia: Flávio Roberto

Câmeras: Flávio Roberto, Lucas de Barros, Diego Lara

Som Direto: R. Oliveira

Montagem: Roberto Pereira

Colorização: Lucas de Barro

Trilha sonora original: Mauro Cézar Cislaghi

Produtora: Tac Filmes

Produção executiva: Flávio Roberto

Vida fora do armário - Direção de Luciano Coelho e Marcelo Munhoz. Curitiba/PR: Coelho Produções Artísticas/Projeto Olho Vivo, 2008, (36min09)

Direção e roteiro: Luciano Coelho e Marcelo Munhoz

Produção: Marcelo Munhoz

Empresa produtora: Coelho Produções Artísticas/

Projeto Olho Vivo

Assistência de câmera e som direto: Bruno Mancuzo

Pesquisa e assistência de produção: Luciana de Morais

A turma - Direção de Filipe Matzembacher e Márcio

Reolon. Porto Alegre/RS: Somos/Avante Filmes, 2011, $(7 \min 43)$

Direção e roteiro: Filipe Matzembacher e Márcio Reolon Produção: Somos - Comunicação, Saúde e Sexualidade

A rua - Direção de Filipe Matzembacher e Márcio Reolon. Porto Alegre/RS: Somos/Avante Filmes, 2011, (7min43)

Direção e roteiro: Filipe Matzembacher e Márcio Reolon Produção: Somos - Comunicação, Saúde e Sexualidade

A rosa - Direção de Filipe Matzembacher e Márcio Reolon. Porto Alegre/RS: Somos/Avante Filmes, 2011, (7min43)
Direção e roteiro: Filipe Matzembacher e Márcio Reolon

Produção: Somos - Comunicação, Saúde e Sexualidade

A âncora - Direção de Filipe Matzembacher e Márcio Reolon. Porto Alegre/RS: Somos/Avante Filmes, 2011, (7min43)

Direção e roteiro: Filipe Matzembacher e Márcio Reolon

Produção: Somos - Comunicação, Saúde e Sexualidade

Preservativo - Direção de Márcio Reolon e Filipe

Matzembacher. Porto Alegre/RS: Avante Filmes, 2011, (5min20)

Argumento: Filipe Matzembacher

Roteiro, Direção, Montagem e Som: Márcio Reolon, Filipe Matzembacher e Samuel Telles

Produção Executiva: Filipe Matzembacher e Márcio Reolon Direção de Fotografia e 0peração de Câmera: Samuel Telles

Ser Mulher - Direção/coordenação: Luciano Coelho.

Curitiba/PR: Projeto Olho Vivo, 2007, (49min18)

Direção/coordenação: Luciano Coelho

Produção/realização: Alunos do projeto Olho Vivo

Translucidx - Direção de Miro Spinelli. Curitiba/PR,

2013 (10min04)

Direção e roteiro: Miro Spinelli

Diretor assistente: Caio Riscado

Produção: Luciano Faccini e Mariana Lopes

Montagem: Miro Spinelli

Assistência de Montagem: Gustavo Pinheiro

Som: Luciano Faccini

Câmera- Imagens adicionais: Gustavo Pinheiro e

Mariana Lopes

Modelos: Isadora Terra, Gustavo Pinheiro, Marina

Laura, Luciano Faccini, Miro Spinelli

Voz over: Caio Riscado

A noite na cidade - Direção de Willy Schumann, 2010 (56min06)

Roteiro e direção: Willy Schumann

Produção: Geni Cruz 


\begin{tabular}{|c|c|}
\hline $\begin{array}{l}\text { Documentary queer in } \\
\text { southern Brazil: general notes }\end{array}$ & $\begin{array}{l}\text { Documental queer en el sur } \\
\text { de Brasil: notas generales }\end{array}$ \\
\hline $\begin{array}{l}\text { Abstract } \\
\text { This article is the result dissertation developed the } \\
\text { Program Master Course Graduate in Communication } \\
\text { from the Federal University of Santa Maria (UFSM). } \\
\text { Conducted a mapping documentaries with gay } \\
\text { characters, gay, bisexual and transgender produced } \\
\text { in southern Brazil between } 2000 \text { and } 2014 \text {. The } \\
\text { study aimed to analyze the LGBT representations, } \\
\text { trying to understand to what extent these films share } \\
\text { narratives / aesthetic queer . It was observed that } \\
19 \text { documentaries analyzed explore the following } \\
\text { themes: memory / history, generation and aging, } \\
\text { discrimination and resistance and finally, sociability } \\
\text { spaces. There is a set of documentaries engaged } \\
\text { in the political incorporation of another abject in a } \\
\text { gendered citizenship, sexual and heteronormative. } \\
\text { On the other hand, there is a group of experimental } \\
\text { documentaries (performative, poetic and reflective) } \\
\text { willing to break with the intelligibilities and cultural } \\
\text { normativities sex / gender. } \\
\text { Keywords } \\
\text { queer documentary; aesthetics; LGBT; sex / gender. }\end{array}$ & $\begin{array}{l}\text { Resumen } \\
\text { Este artículo es el resultado de tesis desarrolló } \\
\text { el Programa de Maestría Curso de Postgrado en } \\
\text { Comunicación de la Universidad Federal de Santa María } \\
\text { (UFSM). Llevó a cabo un mapeo de documentales con } \\
\text { personajes homosexuales, gays, bisexuales y trans } \\
\text { producido en el sur de Brasil entre } 2000 \text { y 2014. El } \\
\text { objetivo del estudio fue analizar las representaciones } \\
\text { LGBT, tratando de comprender en qué medida estas } \\
\text { películas comparten narrativas / extraña estética . Se } \\
\text { observó que 19 documentales analizados explorar los } \\
\text { siguientes temas: la memoria / historia, la generación y } \\
\text { el envejecimiento, la discriminación y la resistencia y, } \\
\text { por último, los espacios de sociabilidad. Hay una serie } \\
\text { de documentales dedicados a la incorporación política } \\
\text { de otro absoluta en una ciudadanía de género, sexual } \\
\text { y heteronormative. Por otro lado, hay un grupo de } \\
\text { documentales experimentales (performativas, poéticos } \\
\text { y reflexivos) dispuestos a romper con el inteligibilidades } \\
\text { y normatividades culturales sexo / género. } \\
\text { Palabras clave } \\
\text { queer documental; la estética; LGBT; sexo / género. }\end{array}$ \\
\hline
\end{tabular}




\section{Expediente}

A revista E-Compós é a publicação científica em formato eletrônico da Associação Nacional dos Programas de Pós-Graduação em Comunicação (Compós). Lançada em 2004, tem como principal finalidade difundir a produção acadêmica de pesquisadores da área de Comunicação, inseridos em instituições do Brasil e do exterior.

\section{E-COMPÓS I www.e-compos.org.br I E-ISSN 1808-2599}

Revista da Associação Nacional dos Programas de Pós-Graduação em Comunicação. Brasília, v.19, n.2, maio/ago. 2016. A identificação das edições, a partir de 2008, passa a ser volume anual com três números. Indexada por Latindex I www.latindex.unam.mx

\section{CONSELHO EDITORIAL}

\section{Alexandre Farbiarz, Universidade Federal Fluminense, Brasi}

Alexandre Rocha da Silva, Universidade Federal do Rio Grande do Sul, Brasil Ana Carolina Escosteguy, Pontifícia Universidade Católica do Rio Grande do Sul, Brasil Ana Carolina Rocha Pessôa Temer, Universidade Federal de Goiás, Brasil Ana Regina Barros Rego Leal, Universidade Federal do Piauí, Brasil Andrea França, Pontifícia Universidade Católica do Rio de Janeiro, Brasil André Luiz Martins Lemos, Universidade Federal da Bahia, Brasil Antonio Carlos Hohlfeldt, Pontifícia Universidade Católica do Rio Grande do Sul, Brasil Arthur Ituassu, Pontifícia Universidade Católica do Rio de Janeiro, Brasil Álvaro Larangeira, Universidade Tuiuti do Paraná, Brasil

Ângela Freire Prysthon, Universidade Federal de Pernambuco, Brasil César Geraldo Guimarães, Universidade Federal de Minas Gerais, Brasil Cláudio Novaes Pinto Coelho, Faculdade Cásper Líbero, Brasil Daisi Irmgard Vogel, Universidade Federal de Santa Catarina, Brasil Denize Correa Araujo, Universidade Tuiuti do Paraná, Brasil Eduardo Antonio de Jesus, Pontifícia Universidade Católica de Minas Gerais, Brasil Daniela Zanetti, Universidade Federal do Espírito Santo, Brasil Eduardo Vicente, Universidade de São Paulo, Brasil

Elizabeth Moraes Gonçalves, Universidade Metodista de São Paulo, Brasil Erick Felinto de Oliveira, Universidade do Estado do Rio de Janeiro, Brasil Francisco Elinaldo Teixeira, Universidade Estadual de Campinas, Brasil Francisco Paulo Jamil Almeida Marques, Universidade Federal do Paraná, Brasil Gabriela Reinaldo, Universidade Federal do Ceará, Brasil

Goiamérico Felício Carneiro Santos, Universidade Federal de Goiás, Brasil Gustavo Daudt Fischer, Universidade do Vale do Rio dos Sinos, Brasil Herom Vargas, Universidade Municipal de São Caetano do Sul, Brasil Itania Maria Mota Gomes, Universidade Federal da Bahia, Brasil Janice Caiafa, Universidade Federal do Rio de Janeiro, Brasil Jiani Adriana Bonin, Universidade do Vale do Rio dos Sinos, Brasil
José Afonso da Silva Junior, Universidade Federal de Pernambuco, Brasil José Luiz Aidar Prado, Pontifícia Universidade Católica de São Paulo, Brasil Juçara Gorski Brittes, Universidade Federal de Ouro Preto, Brasil Kati Caetano, Universidade Tuiuti do Paraná, Brasil Lilian Cristina Monteiro França, Universidade Federal de Sergipe, Brasil Liziane Soares Guazina, Universidade de Brasilia, Brasil Luíza Mônica Assis da Silva, Universidade de Caxias do Sul, Brasil Luciana Miranda Costa, Universidade Federal do Pará, Brasil Malena Segura Contrera, Universidade Paulista, Brasil Monica Martinez, Universidade de Sorocaba, Brasil Maria Ataide Malcher, Universidade Federal do Pará, Brasil Marcia Tondato, Escola Superior de Propaganda e Marketing, Brasil Marcel Vieira Barreto Silva, Universidade Federal da Paraiba, Brasil Maria Clotilde Perez Rodrigues, Universidade de São Paulo, Brasil Maria das Graças Pinto Coelho, Universidade Federal do Rio Grande do Norte, Brasil Mauricio Ribeiro da Silva, Universidade Paulista, Brasil

Mauro de Souza Ventura, Universidade Estadual Paulista, Brasil Márcio Souza Gonçalves, Universidade do Estado do Rio de Janeiro, Brasil Micael Maiolino Herschmann, Universidade Federal do Rio de Janeiro, Brasil Mirna Feitoza Pereira, Universidade Federal do Amazonas, Brasil Nísia Martins Rosario, Universidade Federal do Rio Grande do Sul, Brasil Potiguara Mendes Silveira Jr, Universidade Federal de Juiz de Fora, Brasil Regiane Regina Ribeiro, Universidade Federal do Paraná, Brasil Rogério Ferraraz, Universidade Anhembi Morumbi, Brasil Rose Melo Rocha, Escola Superior de Propaganda e Marketing, Brasil Rozinaldo Antonio Miani, Universidade Estadual de Londrina, Brasil Sérgio Luiz Gadini, Universidade Estadual de Ponta Grossa, Brasil Simone Maria Andrade Pereira de Sá, Universidade Federal Fluminense, Brasil Veneza Mayora Ronsini, Universidade Federal de Santa Maria, Brasil Walmir Albuquerque Barbosa, Universidade Federal do Amazonas, Brasil
COMISSÃO EDITORIAL Eduardo Antonio de Jesus, Pontifícia Universidade Católica de Minas Gerais, Brasil I Osmar Gonçalves dos Reis Filho, Universidade Federal do Ceará, Brasi

CONSULTORES AD HOC Alexandre Almeida Barbalho, Universidade Estadual do Ceará, Brasil | Alexandre Rocha da Silva, Universidade Federal do Rio Grande do Sul, Brasil | Bruno Souza Leal, Universidade Federal de Minas Gerais, Brasil I Carlos Eduardo Franciscato, Universidade Federal do Sergipe, Brasil I Eneus T. Barreto Filho, Universidade de São Paulo, Brasil I Felipe da Costa Trotta, Universidade Federal Fluminense, Brasi | Henrique Codato, Universidade Federal do Ceará, Brasil I Ines S. Vitorino Sampaio Universidade Federal do Ceará, Brasil I Jairo Getulio Ferreira, Universidade do Vale do Rio dos Sinos, Brasil I Juliana Freire Gutmann, Universidade Federal da Bahia, Brasil | Júlio César M. Pinto, Pontifícia Universidade Católica de Minas Gerais, Brasil I Lucrecia D. Ferrara, Pontifícia Universidade Católica de São Paulo, Brasil I Marcio V. Serelle, Pontifícia Universidade Católica de Minas Gerais, Brasil I Maria Ignes C. Magno, Universidade Anhemb Morumbi, Brasil I Maria Lilia Dias de Castro, Universidade Federal de Santa Maria, Brasil | Mozahir S. Bruck, Pontifícia Universidade Católica de Minas Gerais, Brasil I Potiguara M. da Silveira Junior, Universidade Federal de Juiz de Fora, Brasil I Sandra Maria L. P. Gonçalves, Universidade Federal do Rio Grande do Sul, Brasil I Suzana Kilpp, Universidade do Vale do Rio dos Sinos, Brasil I Tiago Q. Fausto Neto, Universidade de Brasília, Brasil I Vera Regina V. Franca, Universidade Federal de Minas Gerais, Brasil I Virginia P. S. Fonseca, Universidade Federal do Rio Grande do Sul, Brasil

EQUIPE TÉCNICA ASSISTENTE EDITORIAL Márcio Zanetti Negrini REVISÃo DE TEXTOS Press Revisão I EDITORAÇÃO ELETRÔNICA Roka Estúdio

\section{COMPÓS I www.compos.org.br}

Associação Nacional dos Programas de Pós-Graduação em Comunicação

Presidente

Edson Fernando Dalmonte

Programa de Pós-Graduação em Comunicação

e Cultura Contemporânea - UFBA

edsondalmonte@uol.com.br

Vice-presidente

Cristiane Freitas Gutfreind

Programa de Pós-Graduação em Comunicação Social - PUC-RS cristianefreitas@pucrs.br

Secretário-Geral

Rogério Ferraraz

Programa de Pós-Graduação em Comunicação

Universidade Anhembi Morumbi

rogerioferraraz@anhembimorumbi.edu.br

CONTATO I revistaecompos@gmail.com 